University of Wollongong

Research Online

Faculty of Engineering - Papers (Archive)

Faculty of Engineering and Information

Sciences

$17-7-2006$

\title{
Orientation dependent ferroelectric properties in samarium doped bismuth titanate thin films grown by the pulsed-laser-ablation method
}

\author{
Z. Cheng \\ University of Wollongong, cheng@uow.edu.au \\ C. V. Kannan \\ National Institute for Materials Science, Japan \\ Kiyoshi Ozawa \\ National Institute for Materials Science, Japan, ozawa@uow.edu.au \\ H. Kimura \\ National Institute for Materials Science, Japan \\ Xiaolin Wang \\ University of Wollongong, xiaolin@uow.edu.au
}

Follow this and additional works at: https://ro.uow.edu.au/engpapers

Part of the Engineering Commons

https://ro.uow.edu.au/engpapers/125

\section{Recommended Citation}

Cheng, Z.; Kannan, C. V.; Ozawa, Kiyoshi; Kimura, H.; and Wang, Xiaolin: Orientation dependent ferroelectric properties in samarium doped bismuth titanate thin films grown by the pulsed-laser-ablation method 2006.

https://ro.uow.edu.au/engpapers/125

Research Online is the open access institutional repository for the University of Wollongong. For further information contact the UOW Library: research-pubs@uow.edu.au 


\title{
Orientation dependent ferroelectric properties in samarium doped bismuth titanate thin films grown by the pulsed-laser-ablation method
}

\author{
Zhenxiang Cheng ${ }^{\text {a) }}$ \\ National Institute for Materials Science, 1-2-1, Sengen, Tsukuba-shi, Ibaraki 305-0047, Japan \\ and Institute for Superconducting and Electronics Materials, University of Wollongong, \\ New South Wales 2522, Australia \\ Chinna Venkatasamy Kannan, Kiyoshi Ozawa, and Hideo Kimura \\ National Institute for Materials Science, 1-2-1, Sengen, Tsukuba-shi, Ibaraki 305-0047, Japan \\ Xiaolin Wang \\ Institute for Superconducting and Electronics Materials, University of Wollongong, \\ New South Wales 2522, Australia
}

(Received 1 May 2006; accepted 25 May 2006; published online 17 July 2006)

\begin{abstract}
Samarium doped bismuth titanate thin films with the composition of $\mathrm{Bi}_{3.25} \mathrm{Sm}_{0.75} \mathrm{Ti}_{3} \mathrm{O}_{12}$ and with strong preferred orientations along the $c$ axis and the (117) direction were fabricated on $\mathrm{Pt} / \mathrm{TiO}_{2} / \mathrm{SiO}_{2} / \mathrm{Si}$ substrate by pulsed laser ablation. Measurements on $\mathrm{Pt} / \mathrm{BSmT} / \mathrm{Pt}$ capacitors showed that the $c$-axis oriented film had a small remanent polarization $\left(2 P_{r}\right)$ of $5 \mu \mathrm{C} / \mathrm{cm}^{2}$, while the highly (117) oriented film showed a $2 P_{r}$ value of $54 \mu \mathrm{C} / \mathrm{cm}^{2}$ at an electrical field of $268 \mathrm{kV} / \mathrm{cm}$ and a coercive field $E_{c}$ of $89 \mathrm{kV} / \mathrm{cm}$. This is different from the sol-gel derived $c$-axis oriented $\mathrm{Bi}_{3.15} \mathrm{Sm}_{0.85} \mathrm{Ti}_{3} \mathrm{O}_{12}$ film showing a $2 P_{r}$ value of $49 \mu \mathrm{C} / \mathrm{cm}^{2}$. (C) 2006 American Institute of Physics. [DOI: 10.1063/1.2221918]
\end{abstract}

Since Park et al. showed that fatigue-free La-doped bismuth titanate films $\left(\mathrm{Bi}_{4-x} \mathrm{La}_{x} \mathrm{Ti}_{3} \mathrm{O}_{12}\right.$, or BLT) on Pt electrodes exhibited high remanent polarization $\left(2 P_{r}=24 \mu \mathrm{C} / \mathrm{cm}^{2}\right)$ and required lower deposition temperatures $\left(<750{ }^{\circ} \mathrm{C}\right)$ in comparison to other Bi-layered ferroelectrics (e.g., $\mathrm{SrBiTa}_{2} \mathrm{O}_{9}$ ) in 1999, bismuth layered ferroelectric oxides have attracted a lot of attention as prospective candidates to replace the toxic lead based material $\mathrm{Pb}\left(\mathrm{Zr}_{1-x}, \mathrm{Ti}_{x}\right) \mathrm{O}_{3}$ for application in nonvolatile ferroelectric random access memory (FeRAMS). ${ }^{1-3}$ Following this trend, many lanthanide elements besides La, such as Nd, Sm, and Pr, were tried. ${ }^{4-8}$ Due to the size differences between $\mathrm{Bi}$ and the dopant ions, further structural distortion within the perovskite block will take place, and thus the remanent polarization is enhanced. Usually the structural distortion contributes to the enhancement of the polarization in specially oriented thin films in two different ways. One is to directly raise the intensity of the polarization, and the other is to shift the direction of the polarization vector towards the normal direction of the thin film. Actually, these two effects always take place simultaneously. In the undoped bismuth titanate (BT), the polarization vector almost lies in the $a-b$ plane, which results in a large $P_{r}$ along the $a$ axis (or $b$ axis) and almost negligible $P_{r}$ along the $c$ axis [for pure $\mathrm{Bi}_{4} \mathrm{Ti}_{3} \mathrm{O}_{12}, 2 P_{r}(/ / a$ axis $)=36 \mu \mathrm{C} / \mathrm{cm}^{2}$ and $2 P_{r}(/ / c$ axis $\left.)=4 \mu \mathrm{C} / \mathrm{cm}^{2}\right] .{ }^{9}$ So, to achieve the highest performance in terms of a large sensing margin $\left(2 P_{r}\right)$ in bismuth titanate thin film, one way is to select dopant elements with large differences in their eightfold coordination ionic radii from bismuth, and the other is to fabricate thin films with preferred orientations. To compare the eightfold coordination ionic radii: $\mathrm{Bi}^{3+}, 0.117 \mathrm{~nm} ; \mathrm{Nd}^{3+}, 0.111 \mathrm{~nm}$, and $\mathrm{Sm}^{3+}$, $0.108 \mathrm{~nm}$, so it can be expected that $\mathrm{Nd}$ and Sm doping in

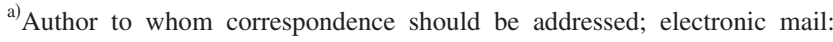
cheng@uow.edu.au
}

bismuth titanate will result in large $P_{r}{ }^{10}$ It has already been experimentally proved that sol-gel derived $c$-axis oriented Nd-doped BT films exhibit a $2 P_{r}$ value of over $100 \mu \mathrm{C} / \mathrm{cm}^{2}{ }^{4,5}$ This unexpected behavior was attributed to the tilting of the $P_{r}$ vector towards the $c$ axis of the film, while other authors showed a quite different result with a zero polarization for $c$-axis oriented Nd-doped BT film made by the pulsed-laser deposition method (PLD). ${ }^{11}$ In the former report, the $c$-axis oriented $\mathrm{Bi}_{3.15} \mathrm{Sm}_{0.85} \mathrm{Ti}_{3} \mathrm{O}_{12}$ films obtained by the sol-gel method showed a polarization of $49 \mu \mathrm{C} / \mathrm{cm}^{2}$. In this letter, the PLD method was used to fabricate $\mathrm{Bi}_{3.25} \mathrm{Sm}_{0.75} \mathrm{Ti}_{3} \mathrm{O}_{12}$ thin films (abbreviated as BSmT hereafter) with different orientations, and their ferroelectric properties were studied in comparison with the results of the sol-gel method.

A target with the composition of $\mathrm{Bi}_{3.41} \mathrm{Sm}_{0.75} \mathrm{Ti}_{3} \mathrm{O}_{12}$, which is intended for the fabrication of $\mathrm{Bi}_{3.25} \mathrm{Sm}_{0.75} \mathrm{Ti}_{3} \mathrm{O}_{12}$ films, with $5 \%$ excess bismuth used to compensate for the loss of bismuth, was prepared by conventional solid state reaction at $1100{ }^{\circ} \mathrm{C}$. The excimer laser is the third harmonic generation of a Nd:YAG (yttrium aluminum garnet) laser with a wavelength of $355 \mathrm{~nm}$ and intensity of $2-3 \mathrm{~J} / \mathrm{cm}^{2}$ at a repetition rate of $10 \mathrm{~Hz}$. The deposition is in $200 \mathrm{mtorr}$ dynamic oxygen at temperatures from 650 to $730{ }^{\circ} \mathrm{C}$. A cooling rate of $15{ }^{\circ} \mathrm{C} / \mathrm{min}$ was used to cool samples to room temperature after deposition. The preferred growth orientations of the films were realized through controlling the deposition temperatures, with the deposition temperatures of $c$-axis oriented and highly (117) oriented films of 710 and $650{ }^{\circ} \mathrm{C}$, respectively. An upper electrode with dimensions of $0.00785 \mathrm{~mm}^{2}$ was covered with a shadow mask and coated by magnetron sputtering. The ferroelectric properties and dielectric properties of the $\mathrm{Pt} / \mathrm{BSmT} / \mathrm{Pt}$ capacitor were measured by an aixACCT EASY CHECH 300 system and an HP 4298A LCR meter, respectively. X-ray diffraction (XRD) of the films was measured by a JEOL JDX-3500 system with 


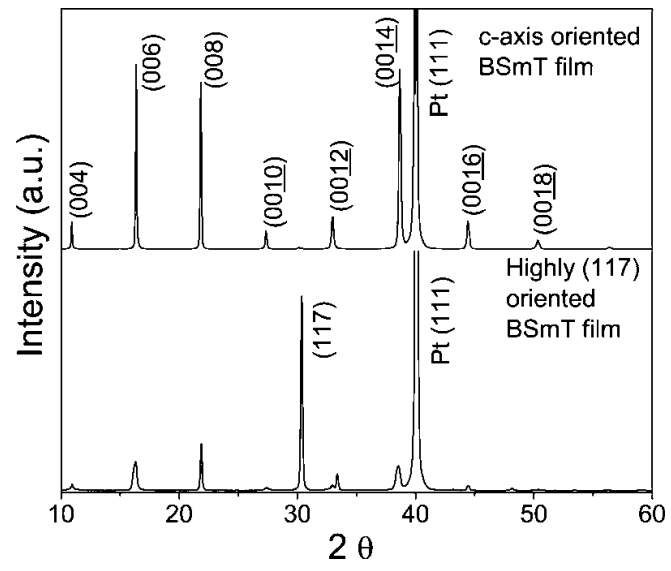

FIG. 1. XRD pattern of the $c$-axis oriented (top) and highly (117) oriented $\mathrm{Bi}_{3.25} \mathrm{Sm}_{0.75} \mathrm{Ti}_{3} \mathrm{O}_{12} / \mathrm{Pt} / \mathrm{Ti} / \mathrm{SiO}_{2} / \mathrm{Si}$ film (bottom).

$\mathrm{Cu} K \alpha$ radiation. The morphology of the films was scanned by a Digital Dimension ${ }^{\mathrm{TM}} 3100$ atomic force microscope in the tapping mode. The thickness of the films was measured by an optical reflection method with a Filmtek ${ }^{\mathrm{TM}} 4000$ system from Scientific Computing International, USA.

In Fig. 1, the XRD pattern shows that the degree of the (001)-type preferential growth, as estimated using the Lotgering orientation factor, is over $99 \%$ for the nominally $c$-axis oriented film, while the degree of (117) preferential growth is much lower. In Fig. 2, the morphology of the $c$-axis oriented BSmT film (a) shows flat layer structured grains with an average dimension of $700 \mathrm{~nm}$, and the highly (117) oriented film (b) shows grains with a dimension of around $150 \mathrm{~nm}$. At temperatures above $700{ }^{\circ} \mathrm{C}$, bismuth titantate has a strong intensity to grow epitaxially on the $\mathrm{Pt}$ (111) face due to the small lattice mismatch between BT (0014) and Pt (111). However, at a lower deposition temperature, the tendency to grow epitaxially on the Pt (111) face is weak. BSmT film will thus show an XRD pattern similar to its ceramic bulk counterpart, of which (117) is the strongest diffraction peak.

Figure 3 shows the polarization-electrical field $(P-E)$ hysteresis loops of a $c$-axis oriented BSmT thin film with a thickness of $234 \mathrm{~nm}$. It should be noted that the electrical field applied on the samples during the measurement could not be high, for otherwise the films would be easily destroyed. It was found that the highly $c$-axis oriented thin film was very difficult to saturate. At an applied voltage of $19 \mathrm{~V}$ (or an electrical field of $812 \mathrm{kV} / \mathrm{cm}$ ), the $\mathrm{Pt} / \mathrm{BSmT} / \mathrm{Pt}$ capacitor shows a remanent polarization $2 P_{r}$ of $5 \mu \mathrm{C} / \mathrm{cm}^{2}$,

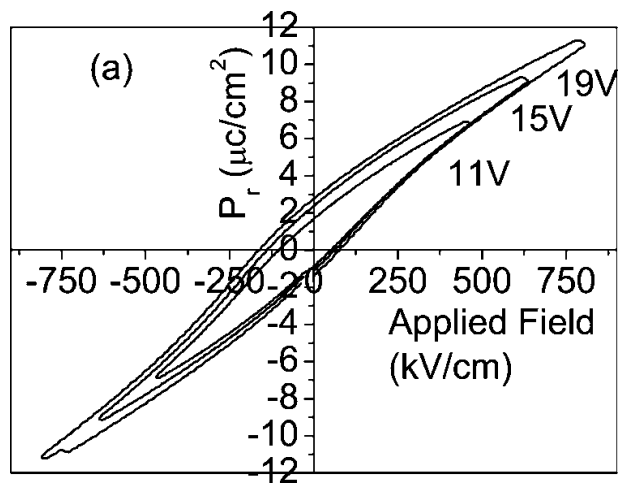

FIG. 3. Hysteresis loops of the highly $c$-axis oriented $\mathrm{Pt} / \mathrm{Bi}_{3.25} \mathrm{Sm}_{0.75} \mathrm{Ti}_{3} \mathrm{O}_{12} / \mathrm{Pt}$ capacitor measured at various applied voltages: 11, 15 , and $19 \mathrm{~V}$.

while the highly (117) oriented film with a thickness of $410 \mathrm{~nm}$ is easily saturated at an applied voltage of $11 \mathrm{~V}$ $(268 \mathrm{kV} / \mathrm{cm})$ with a remanent polarization $2 P_{r}$ of $54 \mu \mathrm{C} / \mathrm{cm}^{2}$, which is higher than the $2 P_{r}$ of $27 \mu \mathrm{C} / \mathrm{cm}^{2}$ for a highly $c$-axis oriented $\mathrm{Bi}_{3.25} \mathrm{La}_{0.75} \mathrm{Ti}_{3} \mathrm{O}_{12}$ capacitor. ${ }^{1}$ At the same time, a low coercive electrical field $\left(E_{c}\right)$ of $89.1 \mathrm{kV} / \mathrm{cm}$ was observed. Figure 4 summarizes the variations of $2 P_{r}$ and $E_{c}$ with applied electrical field for the BSmT capacitor. Structure refinement showed, in undoped BT film and Ladoped BT film (BLT), that the polarization vector almost lies in the $a-b$ plane. Thus the remanent polarization value of highly $c$-axis oriented pure BT and BLT films is less than that of the highly (117) oriented film. For the Nd-doped BT film (BNdT), the remanent polarization of a highly $c$-axis oriented film was much larger than that of the (117) oriented film, due to the shifting of the polarization direction to near the $c$-axis direction as well as further distortion of the Ti-O octahedra. ${ }^{4}$ The small remanent polarization value of our $c$-axis oriented BSmT shows that the Sm doping in BT does not shift the polarization vector from the $a-b$ plane to a direction near the $c$-axis, as occurred with $\mathrm{Nd}$ doping. This result is quite different from the previous result, where the highly $c$-axis oriented $\mathrm{Bi}_{3.15} \mathrm{Sm}_{0.85} \mathrm{Ti}_{3} \mathrm{O}_{12}$ films derived by the sol-gel method showed a $2 P_{r}$ value as high as $49 \mu \mathrm{C} / \mathrm{cm}^{2}{ }^{6}$ A small difference in the compositions cannot be responsible for the large difference in the properties (as the reported sample had the composition $\mathrm{Bi}_{3.15} \mathrm{Sm}_{0.85} \mathrm{Ti}_{3} \mathrm{O}_{12}$, and our sample has the composition $\mathrm{Bi}_{3.25} \mathrm{Sm}_{0.75} \mathrm{Ti}_{3} \mathrm{O}_{12}$ ). A possible reason for the contrary results might be differences in the microstructures caused by the fabrication methods and deposition temperatures. Higher deposition temperatures will
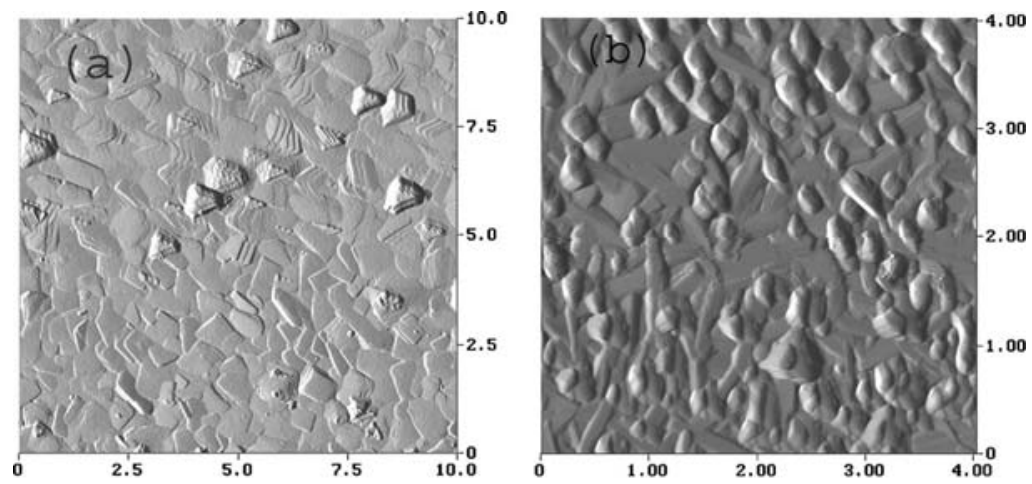

FIG. 2. Morphologies of the highly $c$-axis oriented film (a) and highly (117) oriented $\mathrm{Bi}_{3.25} \mathrm{Sm}_{0.75} \mathrm{Ti}_{3} \mathrm{O}_{12} / \mathrm{Pt} / \mathrm{Ti} / \mathrm{SiO}_{2} / \mathrm{Si}$ film (b) measured by an atomic force microscope in tapping mode.

Downloaded 11 Aug 2006 to 130.130.37.6. Redistribution subject to AlP license or copyright, see http://apl.aip.org/apl/copyright.jsp 


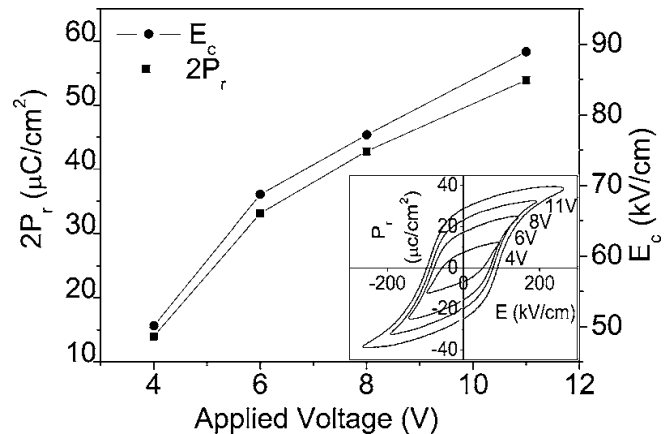

FIG. 4. Variations of $2 P_{r}$ and $E_{c}$ values of the $\mathrm{Pt} / \mathrm{Bi}_{3.25} \mathrm{Sm}_{0.75} \mathrm{Ti}_{3} \mathrm{O}_{12} / \mathrm{Pt}$ capacitor are plotted as a function of the applied voltage. The inset shows hysteresis loops measured at various applied voltages ranging between 4 and $11 \mathrm{~V}$.

produce better crystallinity and larger grain sizes, thus decreasing the density of grain boundaries. The grain size of our sample is around $700 \mathrm{~nm}$, which is much larger than that of films fabricated by the sol-gel method (usually less than $100 \mathrm{~nm}$ ). PLD is a strongly nonequilibrium process, so large stresses always remain in the samples, which is favorable for large polarization. On the other hand, the sol-gel deposition process is an equilibrium crystal growth process, so strain relief can occur successfully. Though it is difficult to analyze the effect of each of the factors while ruling out the others, it is certain that microstructure and strain are the main reasons for the quite different performance of the two films derived from different methods. A similar difference was also observed in Nd-doped BT films. ${ }^{11}$ A high $P_{r}$ value was measured in sol-gel derived highly $c$-axis oriented BNdT film, while no $P_{r}$ was measured in a sample with the same orientation that was fabricated by the PLD method.

The real part of the relative dielectric permittivity $\left[\varepsilon^{\prime}(\omega)\right]$ and the dissipation factor $\left[\varepsilon^{\prime \prime}(\omega) / \varepsilon^{\prime}(\omega)=\tan \delta\right]$ of the capacitor were measured at room temperature as a function of frequency [shown in Fig. 5(a)]. At a frequency of $1 \mathrm{MHz}, \varepsilon^{\prime}(\omega)$ and $\tan \delta$ were 345 and 0.056 , respectively. These values are comparable to those of PZT, SBT, and BLT capacitors. ${ }^{1,12,13}$ Although both $\varepsilon^{\prime}(\omega)$ and $\tan \delta$ decreased
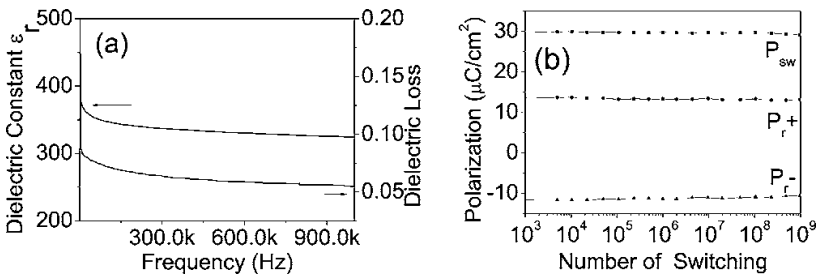

FIG. 5. Frequency dependence of dielectric constant and dielectric loss (a) and electrical fatigue characteristics (b) of $\mathrm{Pt} / \mathrm{Bi}_{3}{ }_{25} \mathrm{Sm}_{0.75} \mathrm{Ti}_{3} \mathrm{O}_{12} / \mathrm{Pt}$ capacitor. The switching voltage during the fatigue test is $\pm 3 \mathrm{~V}$ at a frequency of $5 \mathrm{kHz}$ and the measurement voltage is $5 \mathrm{~V}$. slightly with increasing frequency, there was no sudden change in their values up to $1 \mathrm{MHz}$. All these results indicate that the observed $P-E$ hysteresis behavior of the highly (117) oriented BSmT capacitor originates from the ferroelectric polarization switching of bound charges, not from the response of freely moving charges.

The highly (117) oriented BSmT thin films also show a small leakage current of less than $10^{-6} \mathrm{~A} / \mathrm{cm}^{2}$. The fatiguefree characteristics of the highly (117) oriented BSmT capacitor are shown in Fig. 5(b). The capacitor shows little change either in the switching polarization $\left(P_{\mathrm{sw}}\right)$ or in the remanent polarization $\left(P_{r}^{+}\right)$for up to $10^{9}$ write/read cycles at a switching voltage of $\pm 3 \mathrm{~V}$ at a frequency of $5 \mathrm{kHz}$ and a measurement voltage of $\pm 5 \mathrm{~V}$. The values of $2 P_{r}=\left(P_{r}^{+}\right.$ $-P_{r}^{-}$) of the capacitor was $25.4 \mu \mathrm{C} / \mathrm{cm}^{2}$ at room temperature and remained essentially constant during the fatigue testing, demonstrating an excellent fatigue-free behavior.

In summary, $\mathrm{Bi}_{3.25} \mathrm{Sm}_{0.75} \mathrm{Ti}_{3} \mathrm{O}_{12}$ films with different preferred orientations on platinized silicon were prepared by the PLD method. It was observed that highly $c$-axis oriented BSmT film had a very small remanent polarization, while highly (117) oriented film had a high remanent polarization of up to $54 \mu \mathrm{C} / \mathrm{cm}^{2}$, which is much higher than that of Ladoped BT film. These results are quite different from those for BSmT film derived from the sol-gel method, in which the highly $c$-axis oriented films show a high remanent polarization. The PLD derived BSmT film also shows a good fatigue resistance and small leakage current.

The authors would like to thank the Japanese Society for the Promotion of Science (JSPS) and the Australian Research Council for partial financial support (DP0665873 and DP0558753)

${ }^{1}$ B. H. Park, B. S. Kang, S. D. Bu, T. W. Noh, J. Lee, and W. Jo, Nature (London) 401, 682 (1999).

${ }^{2}$ E. C. Subbarao, J. Phys. Chem. Solids 23, 665 (1962); Phys. Rev. 122, 804 (1961).

${ }^{3}$ P. C. Joshi and S. B. Krupanidhi, Appl. Phys. Lett. 62, 1928 (1993).

${ }^{4}$ U. Chon, H. M. Jang, M. G. Kim, and C. H. Chang, Phys. Rev. Lett. 89, 087601 (2002).

${ }^{5}$ T. Kojima, T. Sakai, T. Watanabe, H. Funakubo, K. Saito, and M. Osada, Appl. Phys. Lett. 80, 2746 (2002).

${ }^{6}$ U. Chon, K. B. Kim, H. M. Jang, and G. C. Yi, Appl. Phys. Lett. 79, 3137 (2001).

${ }^{7}$ U. Chon, J. S. Shim, and H. M. Jang, J. Appl. Phys. 93, 4769 (2003).

${ }^{8}$ Z. X. Cheng, X. L. Wang, C. V. Kannan, K. Ozawa, H. Kimura, T. Nishida, S. J. Zhang, and T. R. Shrout, Appl. Phys. Lett. 88, 132909 (2006).

${ }^{9}$ S. E. Cummins and L. E. Cross, J. Appl. Phys. 39, 2268 (1968).

${ }^{10}$ R. D. Shannon, Acta Crystallogr., Sect. A: Cryst. Phys., Diffr., Theor. Gen. Crystallogr. A32, 751 (1976).

${ }^{11}$ A. Garg, A. Snedden, P. Lightfoot, J. F. Scott, X. Hu, and Z. H. Barber, J. Appl. Phys. 96, 3408 (2004).

${ }^{12}$ R. Dat, J. K. Lee, O. Auciello, and A. I. Kingon, Appl. Phys. Lett. 67, 572 (1995).

${ }^{13}$ H. D. Chen, K. R. Udayakumar, C. J. Gaskey, and L. E. Cross, Appl. Phys. Lett. 67, 3411 (1995) 